\title{
PRÁCTICAS INHALATORIAS Y REDES DE INTERACCIÓN. ANÁLISIS DE ESPÁTULAS ÓSEAS DEL CENTRO DE ARGENTINA
}

\author{
INHALATION PRACTICES AND INTERACTION NETWORKS. ANALYSIS \\ OF BONE SPATULAS FROM CENTRAL ARGENTINA
}

Sebastín PAstora \& Lara Moschettoni ${ }^{B}$

Se presenta un conjunto de espátulas óseas provenientes de la región central de Argentina y se analizan sus vínculos estilísticos con ejemplares afines de los Andes centro-sur y meridionales. El conjunto correspondería al Holoceno Tardío Final y habría formado parte de una parafernalia destinada al consumo inhalatorio de sustancias. En concreto, se definen como espátulas del subtipo "con forma de topo" y aditamentos decorativos laterales con formas de animales. Finalmente, se estudia su distribución macrorregional y se evalúan hipótesis que explican las semejanzas con ejemplares registrados con mayor frecuencia en el Norte Chico de Chile.

Palabras clave: parafernalia para alucinógenos, prácticas y sentidos compartidos, rasgos estilísticos, Holoceno Tardío Final.

This is an analysis of a set of bone spatulas from central Argentina and its stylistic connections with similar specimens from the central-south and southern Andes. Their period of validity would be limited to the end of the late Holocene and they would be part of a paraphernalia used for the inhalation of substances. In particular, these spatulas are thought to be of the "moleshaped" subtype, and include decorative side attachments with animal shapes. Finally, after examining its distribution in the macro-regional space, alternative hypotheses are evaluated in order to explain the similarities with specimens registered more frequently in Chile's Norte Chico.

Keywords: Paraphernalia for hallucinogens, shared practices and senses, stylistic features, end of the Late Holocene.

\section{INTRODUCCIÓN}

Las investigaciones arqueológicas desarrolladas a lo largo de décadas demostraron que durante el Holoceno Tardío Final (Períodos Medio y Tardío, ca. 500-1550 DC) las comunidades originarias de los Andes centro-sur y meridionales hicieron un uso extendido de toda una parafernalia inhalatoria vinculada con el consumo ritual de productos vegetales, en especial de semillas pulverizadas de cebil (Anadenanthera colubrina). Dicho equipamiento incluyó artefactos específicamente relacionados con la manipulación de este tipo de sustancias, como tabletas, tubos y espátulas o cucharillas (Torres 1986; Berenguer 1987; Castillo 1992; Tarragó et al. 1997; Llagostera 2006, 2015; Sprovieri 2008-2009; Horta 2012, 2014; entre otros). Estas últimas fueron elaboradas preferentemente con material óseo y tienen una amplia distribución en contextos arqueológicos del Noroeste Argentino - NOA- (puna, Quebrada de Humahuaca, quebrada del Toro, valle Calchaquí, valle de Abaucán, valle de Iglesia) y Chile (áreas del Norte Chico y Norte Grande) (Ambrosetti 1907, Boman 1908, Latchman 1938, Motsny 1952, Lafón 1956-1957, Sempé 1983, Castillo 1992, Michieli 2013, entre otros).

A Sebastián Pastor, conicet, Centro de Investigación y Transferencia de Catamarca. Prado 366, (4700) San Fernando del Valle de Catamarca, Catamarca, Argentina, e-mail: pastorvcp@yahoo.com.ar

B Lara Moschettoni, Facultad de Humanidades y Artes, Universidad Nacional de Rosario. San Carlos 1450, (2200) San Lorenzo, Santa Fe, Argentina, e-mail: antropolara@gmail.com 
A partir de su variabilidad formal y decorativa, es posible reconocer subtipos e incluso subestilos locales, con una determinada semejanza a nivel de áreas o microrregiones.

En esta contribución se presenta un análisis comparativo, basado en variables tipológicas y estilísticas, de un conjunto de piezas procedentes del centro de Argentina y conservadas en colecciones museológicas, con el fin de evaluar semejanzas y diferencias con ejemplares afines publicados para el NOA y norte de Chile. De este modo, se contrastarán diferentes hipótesis que proponen vínculos entre los habitantes de áreas distantes o bien convergencias culturales en un marco de prácticas rituales y formas ideológicas ampliamente compartidas a nivel de la macrorregión.

Este trabajo se focaliza sobre un subtipo particular, definido como "espátula con forma de topo" (sensu Lafón 1956-1957). Se trata de instrumentos alargados, de sección variable, elaborados con huesos largos de mamíferos, presumiblemente de camélidos. La confección mediante técnicas de pulido borró posibles rasgos que permitan establecer mayores precisiones acerca de las unidades anatómicas y las especies aprovechadas. De acuerdo a los ejemplares completos y a proyecciones obtenidas a partir de fragmentos, se estima un rango de longitud de 13 a $25 \mathrm{~cm}$ para este tipo de objetos. Asimismo, presentan dos extremos aparentemente funcionales: el primero con forma de espátula o cuchara y el segundo de topo o punzón, dada su terminación aguzada (fig. 1). Debajo de la espátula se disponen dos aditamentos o aletas laterales, posiblemente de carácter decorativo. El extremo aguzado pudo usarse como topo o alfiler para sujetar las vestimentas (Ambrosetti 1907, Boman 1908, Motsny 1952) o bien como herramienta para el tejido (Latchman 1938, Marengo 1954), alternativas no excluyentes. En cuanto al sector de la espátula o cuchara, se habría usado para cargar sustancias en forma complementaria con otros artefactos relacionados con las prácticas inhalatorias, como tabletas y tubos (Motsny 1952, Lafón 1956-1957, Castillo 1992).

Aun cuando el extremo aguzado, la cuchara o espátula y los aditamentos laterales son elementos relativamente constantes, se reconocen variaciones a nivel de conjuntos o piezas individuales que justifican la distinción de agrupamientos menores al interior de este subtipo de espátula ósea. Las aletas laterales, por ejemplo, pueden consistir en simples insinuaciones hasta representaciones zoomorfas realistas, con una serie de situaciones intermedias en cuanto al grado de natura-

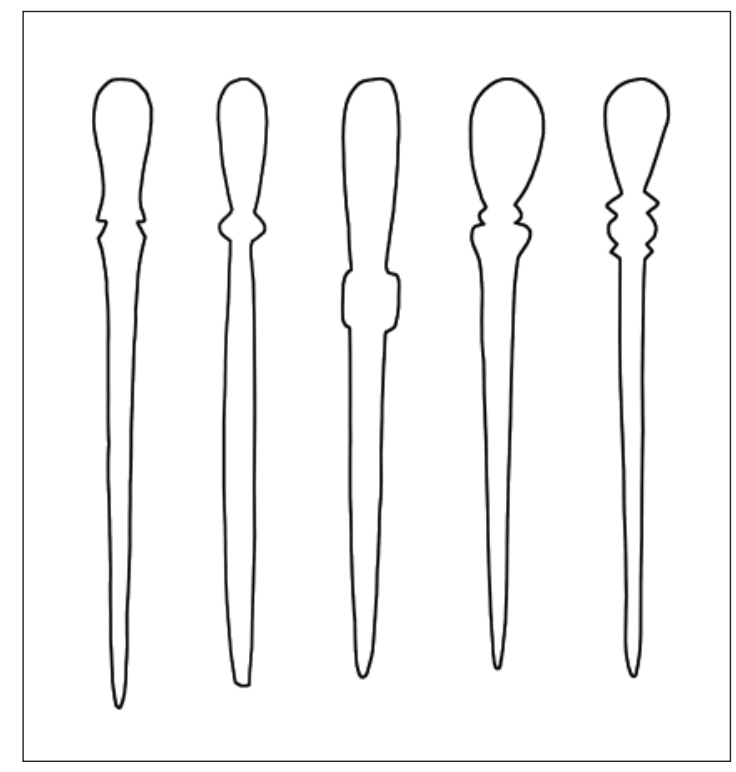

Figura 1. Morfología de las espátulas óseas del subtipo "con forma de topo" en los Andes centro-sur y meridionales. Figure 1. Morphology of bone spatulas of the "mole-shaped" subtype in the central-south and southern Andes.

lismo o abstracción (fig. 2). Entre las representaciones más realistas, se reconocen figuras de felinos y otros animales con rasgos felinizados. En efecto, las posibles figuras de roedores o peces suelen presentar el cuerpo relleno con puntos grabados que se interpretan como manchas felínicas (figs. 3 y 4) (Latchman 1938, Serrano 1945, Lafón 1956-1957, Castillo 1992, entre otros).

\section{“ESPÁTULAS CON FORMA DE TOPO" Y ADITAMENTOS ZOOMORFOS LATERALES}

Un análisis de distribución revela que las "espátulas con forma topo" y los aditamentos zoomorfos laterales integraron contextos arqueológicos mayoritariamente concentrados en el Norte Chico de Chile. En particular, las áreas de procedencia comprenden el valle de Elqui y la costa en torno a La Serena. Con menos frecuencia se suceden hallazgos a lo largo de la costa hacia el norte, entre Bahía Salada y Chañaral (figs. 3 y 5). Por lo general, se hallan en depósitos funerarios, donde suelen asociarse a otros componentes de la parafernalia inhalatoria, incluso con espátulas óseas de otros subtipos. Su cronología sería posterior a 1200 DC, incluido el Período Inka (Castillo 1992). 

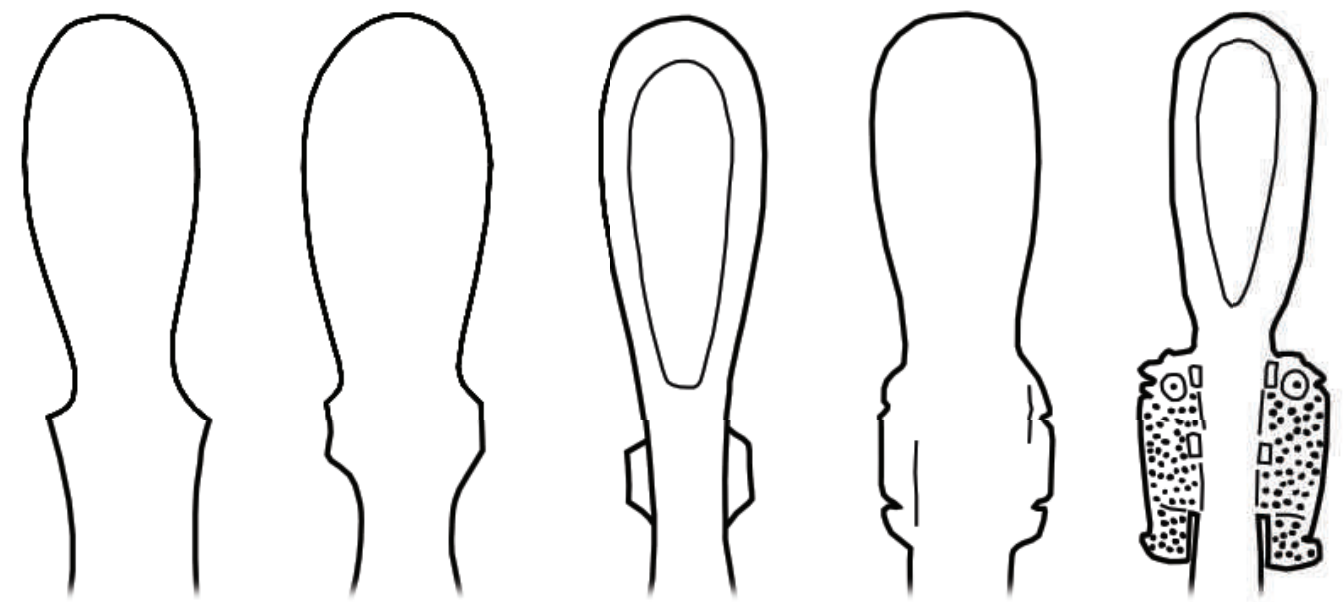

Figura 2. Variaciones en el diseño de los aditamentos o aletas laterales, en piezas de los Andes centro-sur y meridionales. Figure 2. Variations of the design of lateral attachments or fins, in pieces from the central-south and southern Andes.

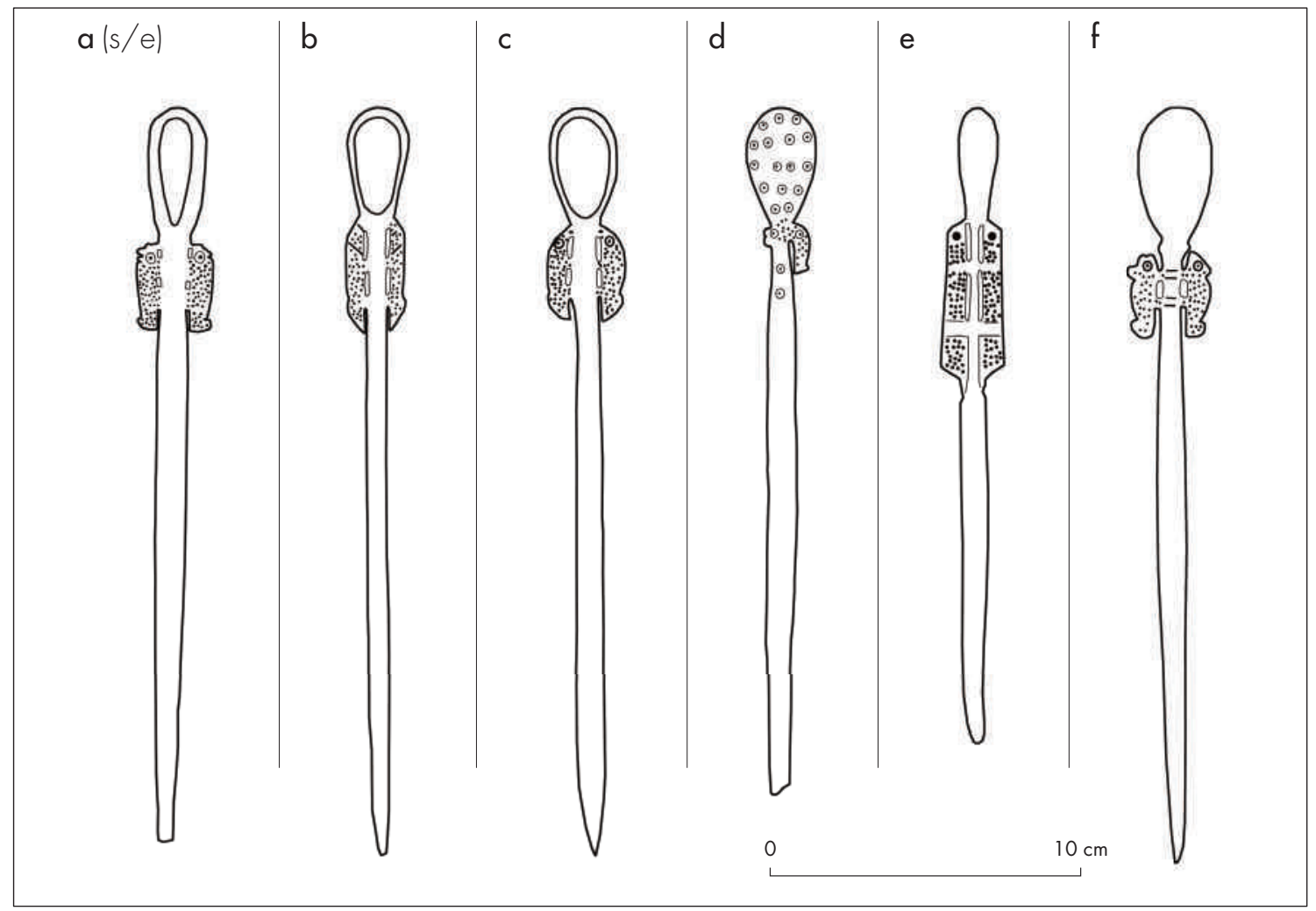

Figura 3. "Espátulas con forma de topo" y zoomorfos laterales en el Norte Chico de Chile: a) El Olivar; b-c) Punta de Piedra; d) Caldera; e) Bahía Obispo; f) Bahía Salada (apud Castillo 1992). Figure 4. "Mole-shaped spatulas" and lateral zoomorphic details from Chile’s Norte Chico: a) El Olivar; b-c) Punta de Piedra; d) Caldera; e) Bahía Obispo; f) Bahía Salada (according to Castillo 1992). 


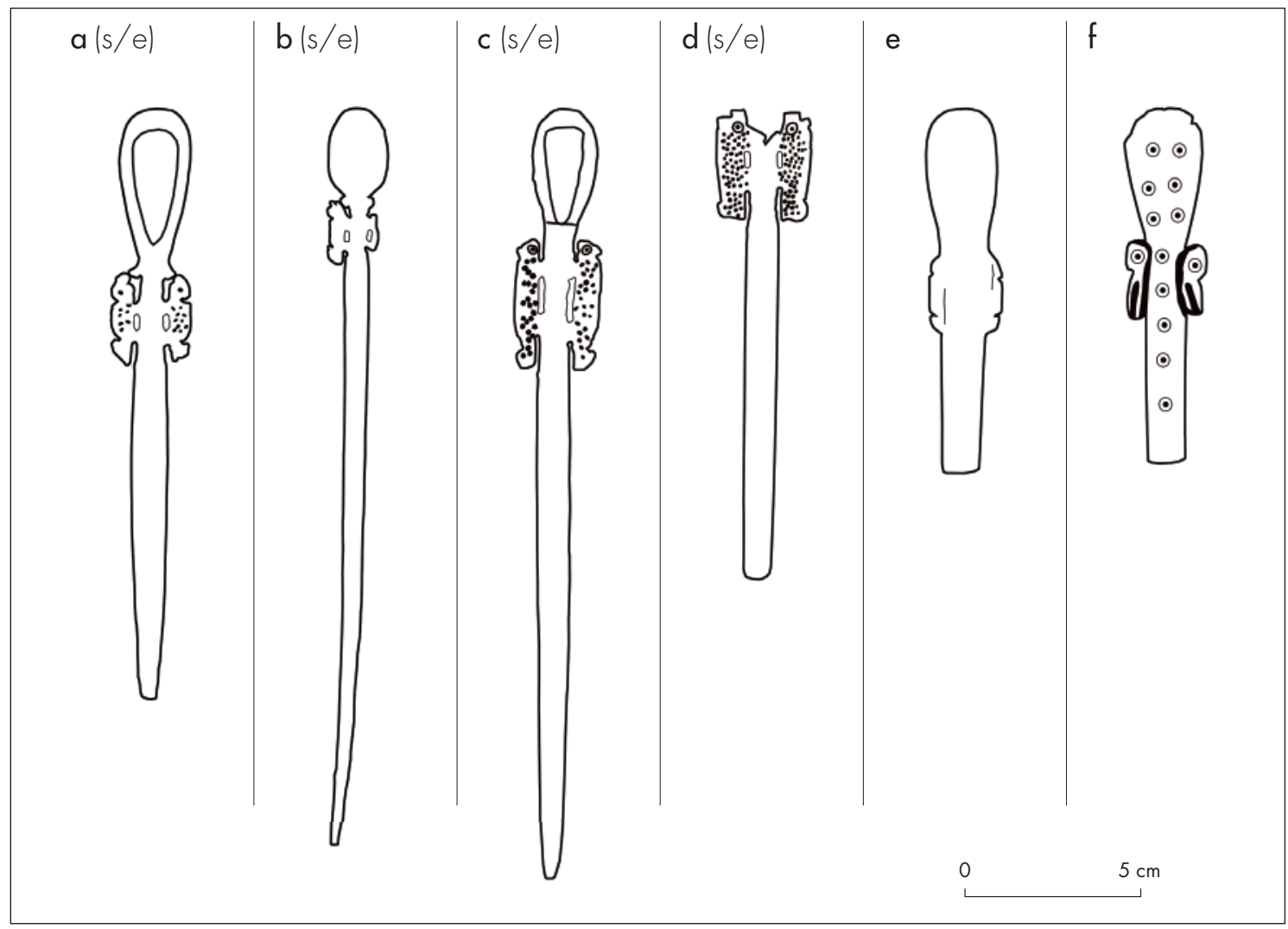

Figura 4. "Espátulas con forma de topo" y zoomorfos laterales en la región atacameña de Chile y Noroeste Argentino: a-c) Taltal, Calama (Latchman 1938); d) Pucará de Rinconada (Pazos \& Giannoni 1969); e) La Paya (Ambrosetti 1907); f) Mishma $n^{\circ} 7$ (Sempé 1983). Figure 5. "Mole-shaped spatulas" and lateral zoomorphic details from the Atacama desert region of Chile and from Northwestern Argentina: a-c) Taltal, Calama (Latchman 1938); d) Pucará de Rinconada (Pazos \& Giannoni 1969); e) La Paya (Ambrosetti 1907); $f$ ) Mishma nº 7 (Sempé 1983).

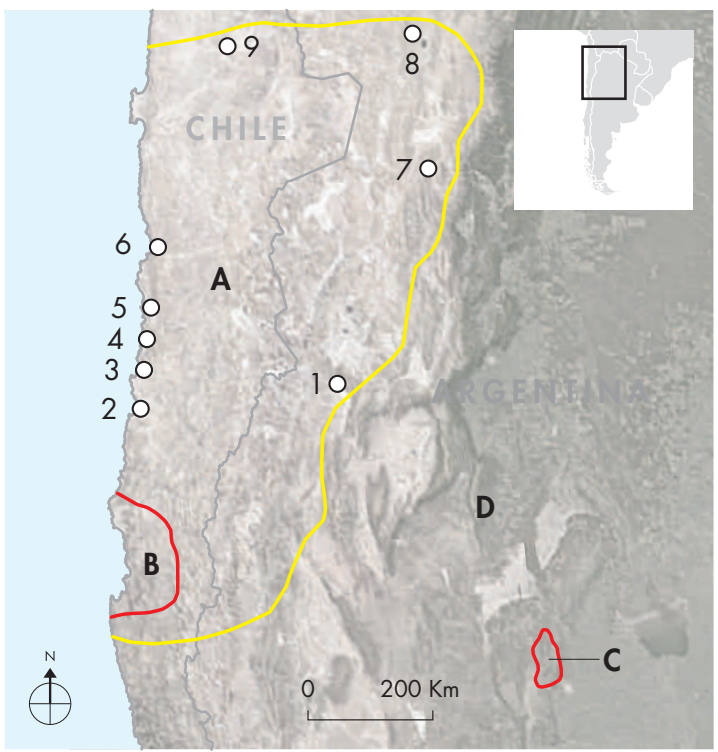

4 Figura 5. Color amarillo: a) distribución global de las "espátulas con forma de topo" (de diferentes variedades) en los Andes centro-sur y meridionales. Color rojo: distribución de las espátulas del subtipo "con zoomorfos laterales"; b) valle de Elqui y costa de La Serena; c) sierras de Córdoba y piedemonte oriental; 1) Mishma n 7;2) Bahía Salada; 3) Caldera; 4) Bahía Obispo; 5) Chañaral; 6) Taltal; 7) La Paya; 8) Pucará de Rinconada; 9) Calama: el punto D señala a las sierras de Ancasti (Catamarca), zona donde crece naturalmente el cebil. Figure 3. In yellow: a) Global distribution of the "mole-shaped spatulas" (different varieties) in the central-south and southern Andes. In red: distribution of spatulas of the subtype "with lateral zoomorphic details”; b) Elqui Valley and coast of La Serena; $c$ ) Córdoba mountain ranges and eastern piedmont; 1) Mishma $n^{\circ} 7$; 2) Bahía Salada; 3) Caldera; 4) Bahía Obispo; 5) Chañaral; 6) Taltal; 7) La Paya; 8) Pucará de Rinconada; 9) Calama: the D point indicates the Ancasti mountain range (Catamarca), where the cebil tree grows naturally. 
Hacia el norte, en la región atacameña, las piezas con tallas zoomorfas son menos comunes y se consideran objetos importados o debidos a influencias desde el Norte Chico (figs. 4 a-c; Latchman 1938), mientras que la referencia más septentrional corresponde a la localidad de Calama (fig. 3; Latchman 1938). En cuanto al NOA, los registros son mínimos. La pieza mejor definida procede del pucará de Rinconada, puna de Jujuy, ubicado a la misma latitud de Calama (figs. $4 \mathrm{~d}$ y 5; Pazos \& Giannoni 1969). Por su parte, las aletas de una de las 14 espátulas recuperadas por Ambrosetti (1907) en La Paya, valle Calchaquí (Salta), consisten en representaciones zoomorfas muy esquemáticas (figs. $4 \mathrm{e}$ y 5). Por último, en el sitio inka Mishma número 7, valle de Abaucán (Catamarca), se identificó una pieza con aletas que representan zoomorfos esquemáticos (posiblemente aves), además de diseños sobre la superficie de la espátula consistentes en pequeños círculos con punto central (figs. 4f y 5; Sempé 1983). Estos diseños circulares son comunes en la decoración de espátulas (fig. 3d) y otros objetos óseos de los Andes centro-sur y meridionales (Ambrosetti 1907, Casanova 1939, Bennett 1946, Ibarra 1971, Castillo 1992, entre otros).

\section{Espátulas óseas en la región central de Argentina}

Se realizó un registro de publicaciones y colecciones arqueológicas de museos de Córdoba, registro que reúne un total de 15 espátulas óseas procedentes de los valles y piedemontes orientales de la serranía de aquella provincia (fig. 6). Un fragmento de las costas del lago San Roque (valle de Punilla) fue publicado por Serrano (1945); otro, de la costa del lago Los Molinos (valle de Los Reartes), por Marcellino et al. (1967) (figs. $7 \mathrm{f} \mathrm{y} \mathrm{g}$ ). Las 13 piezas restantes están depositadas en el Museo Arqueológico Numba Charava (Villa Carlos Paz), el Museo Camín Cosquín (Cosquín), el Museo Jesuítico Nacional (Jesús María) y el Museo Arqueológico Provincial Aníbal Montes (Río Segundo) (tabla 1). Más allá de la localidad de procedencia de cada objeto, no se conocen mayores datos contextuales, ya que se trata en todos los casos de hallazgos superficiales o producto de excavaciones asistemáticas.

Tanto las características generales de los sitios arqueológicos (emplazamientos, rasgos ergológicos y estilísticos de los restos superficiales y estratificados) como los detalles técnicos y decorativos (afines a otros tipos de instrumentos óseos de los mismos contextos) permiten

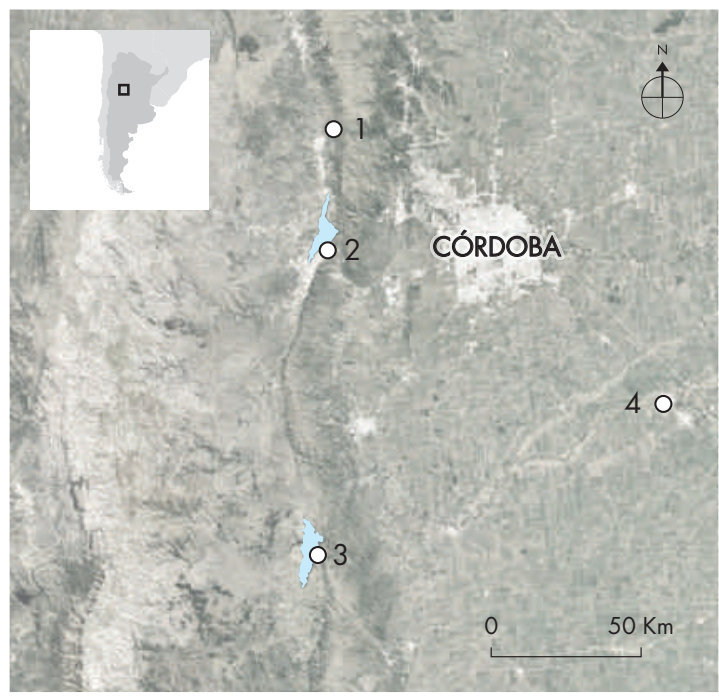

Figura 6. Sitios de procedencia de las "espátulas con forma de topo" y zoomorfos laterales, conservadas en colecciones museológicas del centro de Argentina: 1) La Mandinga, Cosquín; 2) costas del lago San Roque; 3) costas del lago Los Molinos; 4) Río Segundo. Figure 6. Points of origin of the "mole-shaped spatulas" and artifacts with lateral zoomorphic details kept in museum collections in Central Argentina: 1) La Mandinga, Cosquín; 2) San Roque Lake shore; 3) Los Molinos Lake shore; 4) Río Segundo.

asociarlos con una cronología del Período Prehispánico Tardío Final de la secuencia local, ca. 900-1550 DC. Esta estimación de grano grueso se ajusta a la información actualmente disponible, sin descartar que el período de vigencia de la tradición de espátulas óseas en la región fuera aún más acotado (y eventualmente próximo al momento de expansión inka y del imperio español). Nuevas excavaciones y dataciones radiocarbónicas de muestras extraídas directamente de los artefactos permitirán precisar este rango cronológico en el futuro.

Las espátulas óseas del centro de Argentina son afines al subtipo "con forma de topo", con el detalle adicional de que las aletas laterales consisten siempre en representaciones zoomorfas más o menos naturalistas. En los casos de mayor abstracción, se dificulta la identificación de las especies animales; no obstante, otras representaciones son más realistas y resultan compatibles con felinos y lagartos. Los primeros se reconocen por sus siluetas, ya que faltan otros detalles como los colmillos, garras y manchas de la piel, así como la presencia de actitudes diferentes de la pasividad (figs. 7 y 8 ).

Los diseños grabados sobre las superficies de la espátula y topo (de una o ambas caras) constituyen 


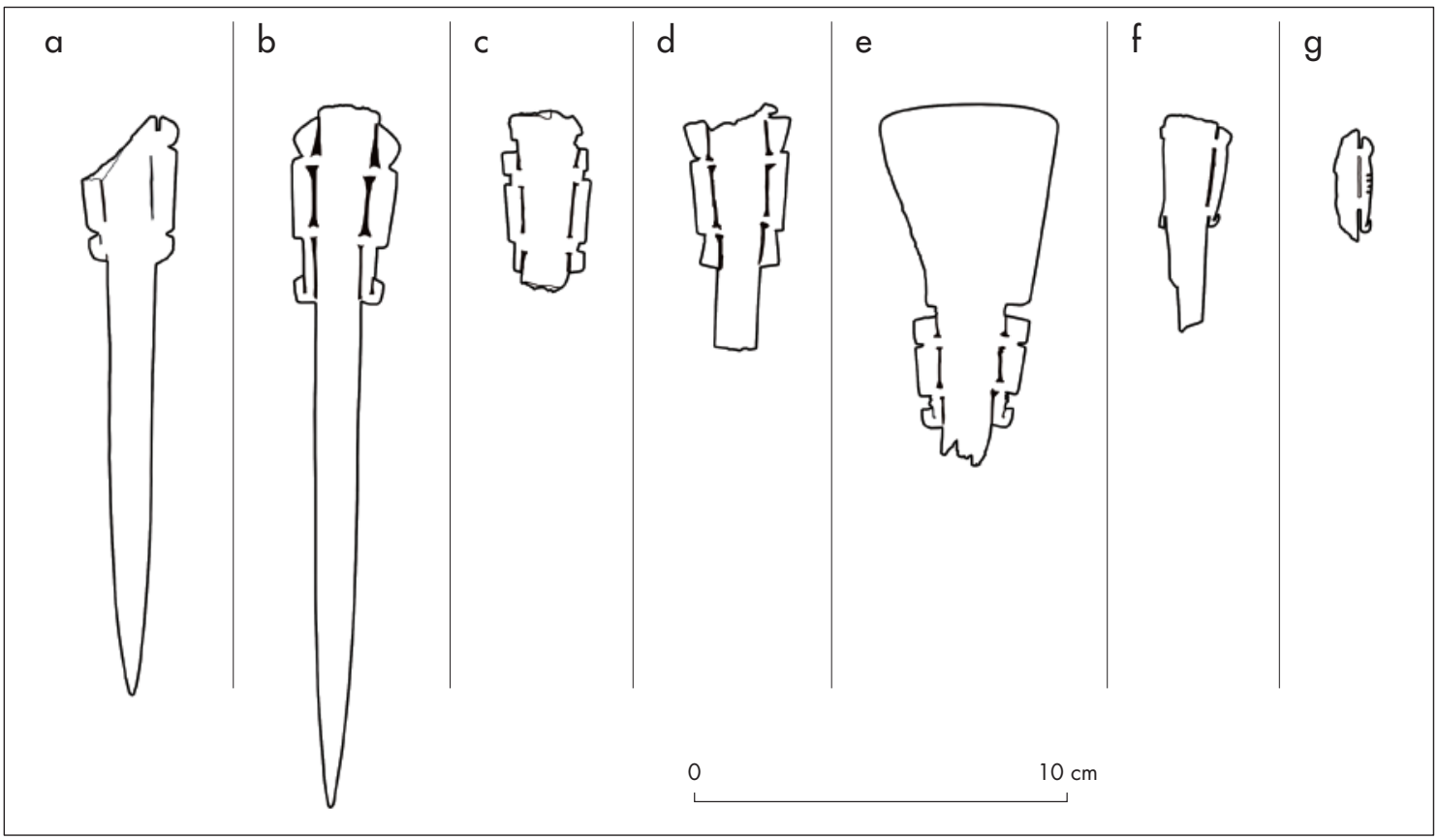

Figura 7. "Espátulas con forma de topo" y zoomorfos laterales del centro de Argentina: a) pieza $n^{\circ} 8$, San Roque; b-c) piezas $n^{\circ} 1$ y 4 , La Mandinga, Cosquín; d-e) piezas 15 y 14, Río Segundo; f) pieza n 12, San Roque (Serrano 1945); g) pieza n 13, Los Molinos (Marcellino et al. 1967). Figure 7. "Mole-shaped spatulas" and artifacts with lateral zoomorphic details from Central Argentina: a) piece $n^{\circ} 8$, San Roque; $\boldsymbol{b}$-c) pieces $n^{\circ} 1$ and 4, La Mandinga, Cosquín; d-e) pieces 15 and 14, Río Segundo; f) piece $n^{\circ}$ 12, San Roque (Serrano 1945); g) piece $n^{\circ} 13$, Los Molinos (Marcellino et al. 1967).

rasgos poco frecuentes, registrados solo en tres piezas. La primera está fragmentada y procede de Cosquín (valle de Punilla). De la cara anterior, a la altura de los zoomorfos laterales, se ejecutó una imagen en negativo consistente en volutas alineadas, también registrada en la decoración de otros artefactos óseos (figs. 9, 10 y 11). La segunda pieza, recolectada en las costas del lago San Roque, está completa y se conserva en el Museo Jesuítico Nacional. De ambas caras se grabaron motivos lineales y circulares, entre ellos la indicación de los ojos de los zoomorfos (fig. 12).

Por último, la tercera espátula también está completa, procede de San Roque y se conserva en el Museo Arqueológico Numba Charava. De la cara posterior, el carácter felínico de los zoomorfos fue enfatizado con puntos grabados sobre el cuerpo, que señalan las manchas u ocelos de un felino moteado como el jaguar (Panthera onca) o gato del monte (Leopardus geoffroyi) (fig. 13a). Este detalle no se repite en la cara anterior, donde otros grabados se combinan con las siluetas de los felinos para producir un diseño anatrópico o de doble lectura (González 1974, Gordillo 2009). En la segunda lectura, los felinos laterales pasan a representar las extremidades de un lagarto en vista aérea, en cuya resolución también participan la forma del contorno de la pieza y los grabados punteados y lineales que, por omisión o técnica de negativo, denotan la cola alargada y terminada en punta. En la parte inferior del topo, a continuación de la cola del lagarto, otros diseños grabados sugieren la figura de un pez (figs. 13b y 14).

\section{Acerca de la distribución de las "espátulas con forma de topo" y zoomorfos laterales}

A continuación se intenta comprender las similitudes entre las piezas cordobesas y algunas espátulas procedentes del Norte Chico de Chile, sin presencia o con muy pocos ejemplares afines en las regiones intermedias (entre el norte de Cuyo y el sur del NOA). Esta problemática es abordada a partir de la valoración de las consecuencias o implicaciones de tres hipótesis disímiles.

Según la primera, como se planteó para el Norte Grande chileno (Latchman 1938), las espátulas de este 
Tabla 1. Espátulas óseas de la región central de Argentina. Procedencias: LM: La Mandinga (centro del valle de Punilla); sR: costas del lago San Roque (sur del valle de Punilla); LMo: costas del lago Los Molinos (valle de Los Reartes); Rs: Río Segundo (piedemonte-llanura oriental de Córdoba). Técnicas de ejecución de las aletas: CA: calado; GR: grabado; PU: pulido. Repositorio: MCC: Museo Camín Cosquín; MNCH: Museo Numba Charava; MjN: Museo Jesuítico Nacional; mam: Museo Arqueológico Provincial Aníbal Montes. Table 1. Bone spatulas from central Argentina. Origins: LM: La Mandinga (center of the Punilla valley); SR: San Roque lake shore (south of the Punilla valley); LMo: Los Molinos lake shore (Los Reartes valley); Rs: Río Segundo (Córdoba's eastern plains-piedmont). Execution technique of the fins: CA: fretwork; GR: engraving; PU: polishing. Repositories: MCC: Museo Camin Cosquin; мNCH: Museo Numba Charava; mJN: Museo Jesuítico Nacional; mam: Museo Arqueológico Provincial Aníbal Montes.

\begin{tabular}{|c|c|c|c|c|c|c|c|}
\hline $\mathrm{N}^{\circ}$ & PROC. & $\begin{array}{l}\text { LARGO/ANCHO } \\
\text { MÁXIMO. } \\
\text { TOTAL O } \\
\text { (ESTIMADO) }\end{array}$ & $\begin{array}{c}\text { FORMA DEL } \\
\text { RECEPTÁCULO }\end{array}$ & $\begin{array}{c}\text { LARGO/ANCHO } \\
\text { RECEPTÁCULO. } \\
\text { TOTAL O } \\
\text { (ESTIMADO) }\end{array}$ & $\begin{array}{c}\text { LARGO } \\
\text { ALETAS. TOTAL } \\
\text { O (ESTIMADO) }\end{array}$ & $\begin{array}{c}\text { TECS. DE } \\
\text { EJECUCIÓN DE } \\
\text { LAS ALETAS }\end{array}$ & $\begin{array}{c}\text { REF./ } \\
\text { REPOSITORIO }\end{array}$ \\
\hline 1 & LM & $16,5 / 2,3 \mathrm{~cm}$ & Irregular & $4,4 / 2,3 \mathrm{~cm}$ & $4,1 \mathrm{~cm}$ & CA-GR-PU & MCC \\
\hline 2 & LM & $(16) /(3 \mathrm{~cm})$ & - & - & $3,3 \mathrm{~cm}$ & CA-GR-PU & MCC \\
\hline 3 & LM & (13) / (3,2 cm) & - & - & $(3,2 \mathrm{~cm})$ & PU & MCC \\
\hline 4 & LM & $-/(2.5 \mathrm{~cm})$ & - & - & $3,1 \mathrm{~cm}$ & GR-PU & MCC \\
\hline 5 & LM & $-/(4,5 \mathrm{~cm})$ & - & - & $(4 \mathrm{~cm})$ & GR-PU & $\mathrm{MCC}$ \\
\hline 6 & SR & $-/ 4,8 \mathrm{~cm}$ & Trapezoidal & $4,7 / 4,8 \mathrm{~cm}$ & $2,8 \mathrm{~cm}$ & CA-PU & MCC \\
\hline 7 & SR & $19,9 / 3,2 \mathrm{~cm}$ & Irregular & $5,3 / 3,2 \mathrm{~cm}$ & $4,3 \mathrm{~cm}$ & GR-PU & $\mathrm{MNCh}$ \\
\hline 8 & SR & $(18,5) /(3,2 \mathrm{~cm})$ & - & - & $3,6 \mathrm{~cm}$ & CA-GR-PU & MNCh \\
\hline 9 & SR & $-/ 4,8 \mathrm{~cm}$ & Trapezoidal & $6,2 / 4,8 \mathrm{~cm}$ & $(4,3 \mathrm{~cm})$ & CA-GR-PU & $\mathrm{MNCh}$ \\
\hline 10 & SR & $-/ 3,2 \mathrm{~cm}$ & Trapezoidal & $4,3 / 3,2 \mathrm{~cm}$ & $3 \mathrm{~cm}$ & CA-GR-PU & MNCh \\
\hline 11 & SR & $(19) /(2,7 \mathrm{~cm})$ & - & - & $3,2 \mathrm{~cm}$ & CA-GR-PU & MJN \\
\hline 12 & SR & - & - & - & - & GR-PU & Serrano 1945 \\
\hline 13 & LMo & - & - & - & - & CA-GR-PU & $\begin{array}{l}\text { Marcellino } \\
\text { et al. } 1967\end{array}$ \\
\hline 14 & RS & $-/ 4,7 \mathrm{~cm}$ & Trapezoidal & $5,4 / 4,7 \mathrm{~cm}$ & $2,9 \mathrm{~cm}$ & CA-GR-PU & MAM \\
\hline 15 & RS & $-/(4 \mathrm{~cm})$ & - & - & $4,1 \mathrm{~cm}$ & CA-GR-PU & MAM \\
\hline
\end{tabular}


a

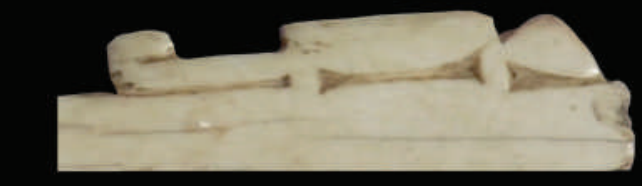

b

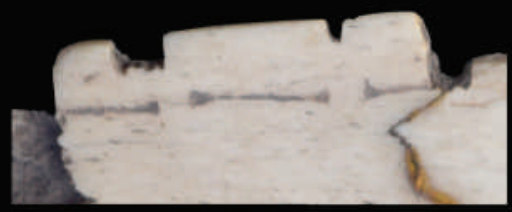

C

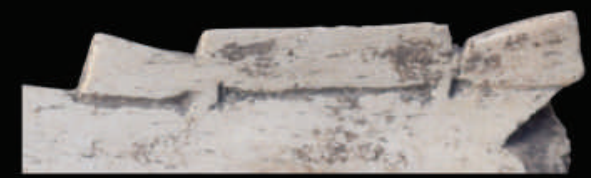

d

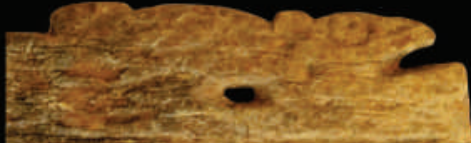

Figura 8. Detalle de los zoomorfos laterales: a) pieza $\mathrm{n}^{\circ} 1, \mathrm{La}$ Mandinga, Cosquín; b) pieza $n^{\circ} 14$, Río Segundo; c) pieza $n^{\circ} 15$, Río Segundo; d) pieza ${ }^{\circ} 11$, San Roque. Figure 8. Close up of zoomorphic details: a) piece $n^{\circ} 1$, La Mandinga, Cosquín; b) piece $n^{\circ} 14$, Río Segundo; c) piece $n^{\circ}$ 15, Río Segundo; d) piece $n^{\circ} 11$, San Roque.

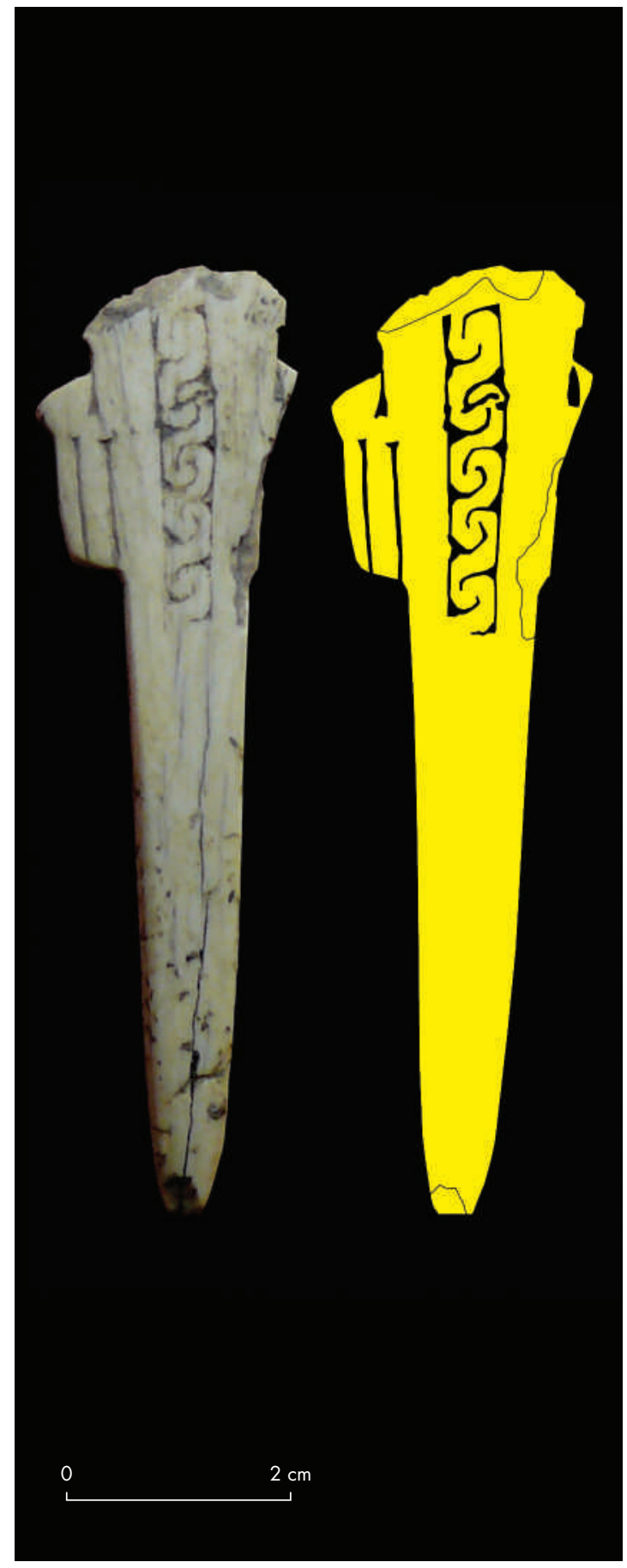

Figura 9. Imagen en negativo de la pieza $n^{\circ} 3$, La Mandinga, Cosquín. Figure 9. Image in negative of the piece $n^{\circ} 3$, La Mandinga, Cosquín. 

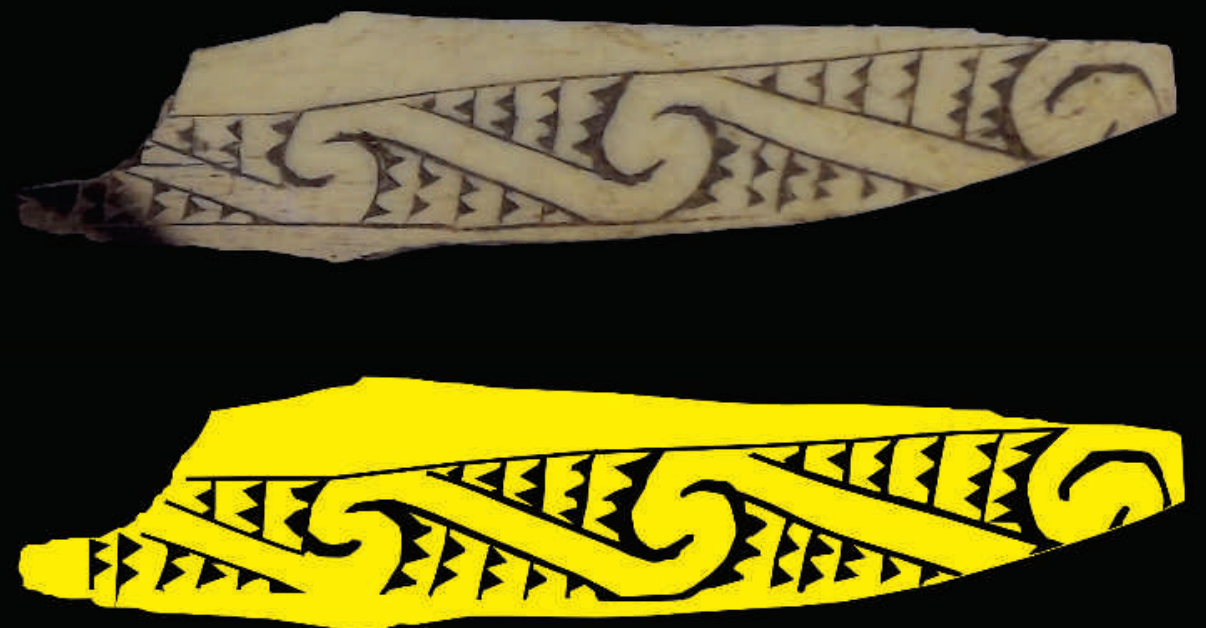

0

$2 \mathrm{~cm}$

Figura 10. Instrumento óseo fragmentado procedente de La Mandinga (Cosquín). Figure 10. Fragmented osseous instrument from La Mandinga (Cosquín).
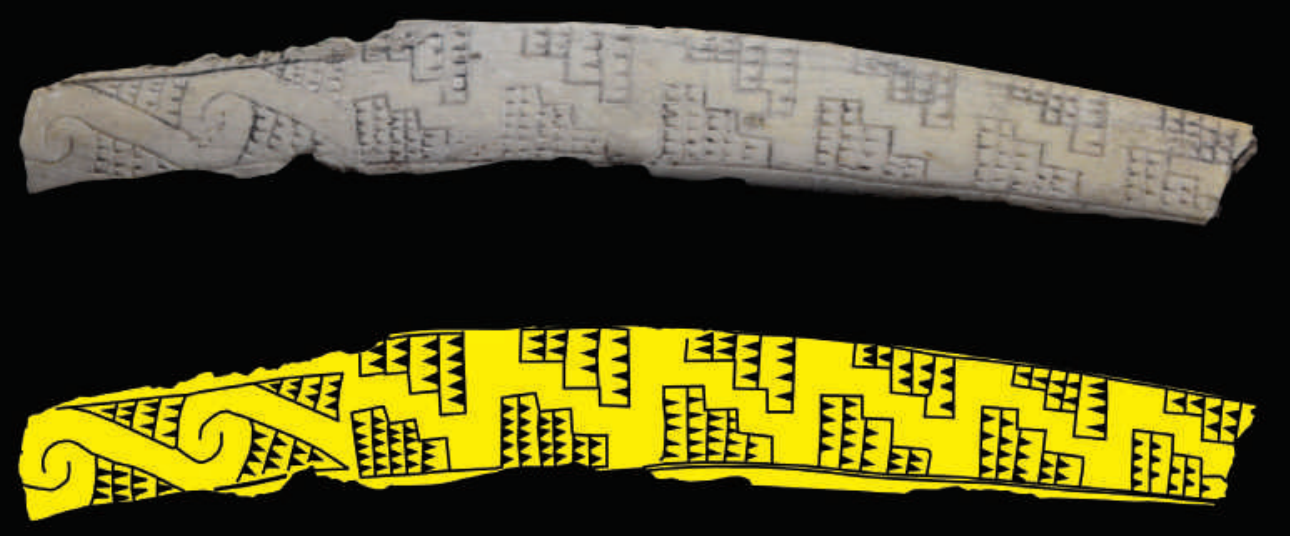

$0 \quad 3 \mathrm{~cm}$

Figura 11. Instrumento fragmentado sobre una costilla (Río Segundo, Córdoba). Figure 11. Fragmented instrument in a rib (Río Segundo, Córdoba). 


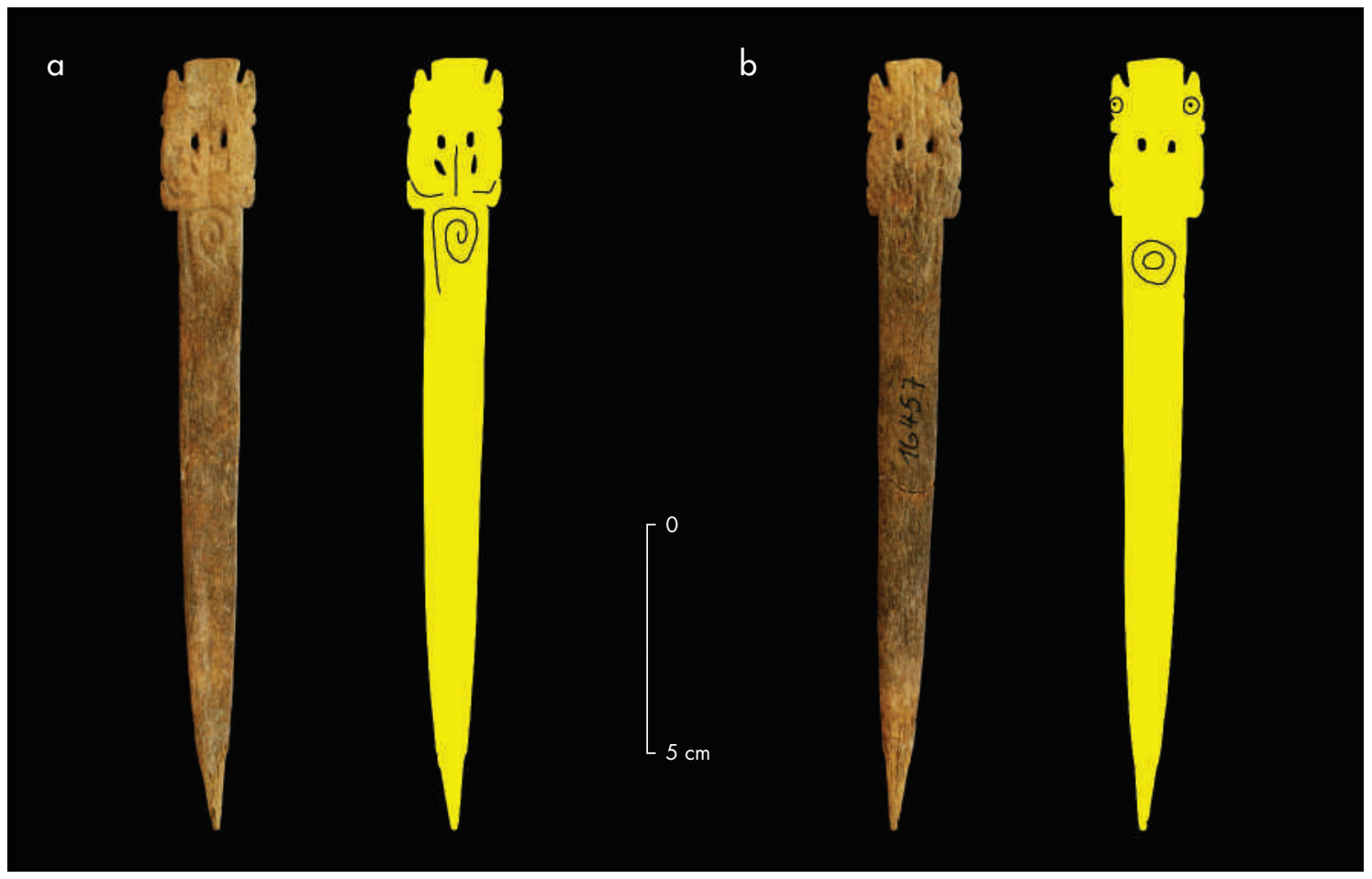

Figura 12. Pieza $n^{\circ}$ 11, San Roque: a) cara posterior; b) cara anterior. Figure 12. piece $n^{\circ} 11$, San Roque: a) back side; $\boldsymbol{b}$ ) front side

a

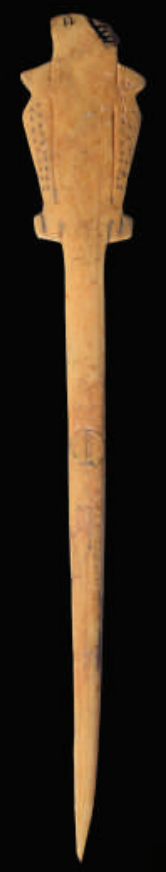

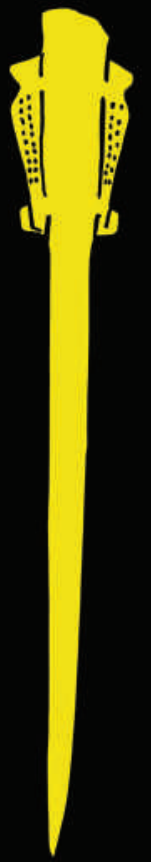

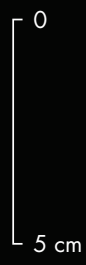

b

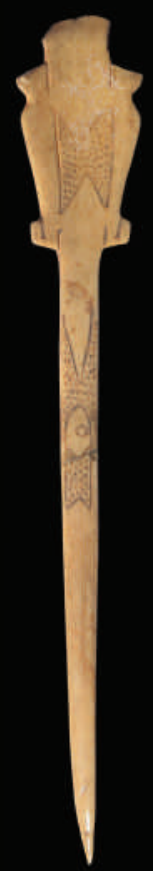

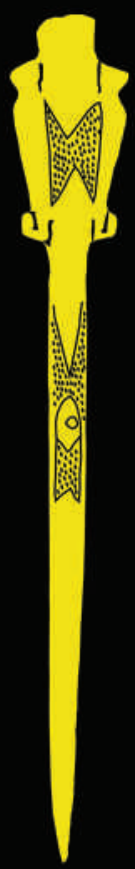

Figura 13. Pieza $n^{\circ}$ 7, San Roque: a) cara posterior; b) cara anterior. Figure 13. piece $n^{\circ}$ 7, San Roque: $\boldsymbol{a}$ ) back side; $\boldsymbol{b}$ ) front side. 


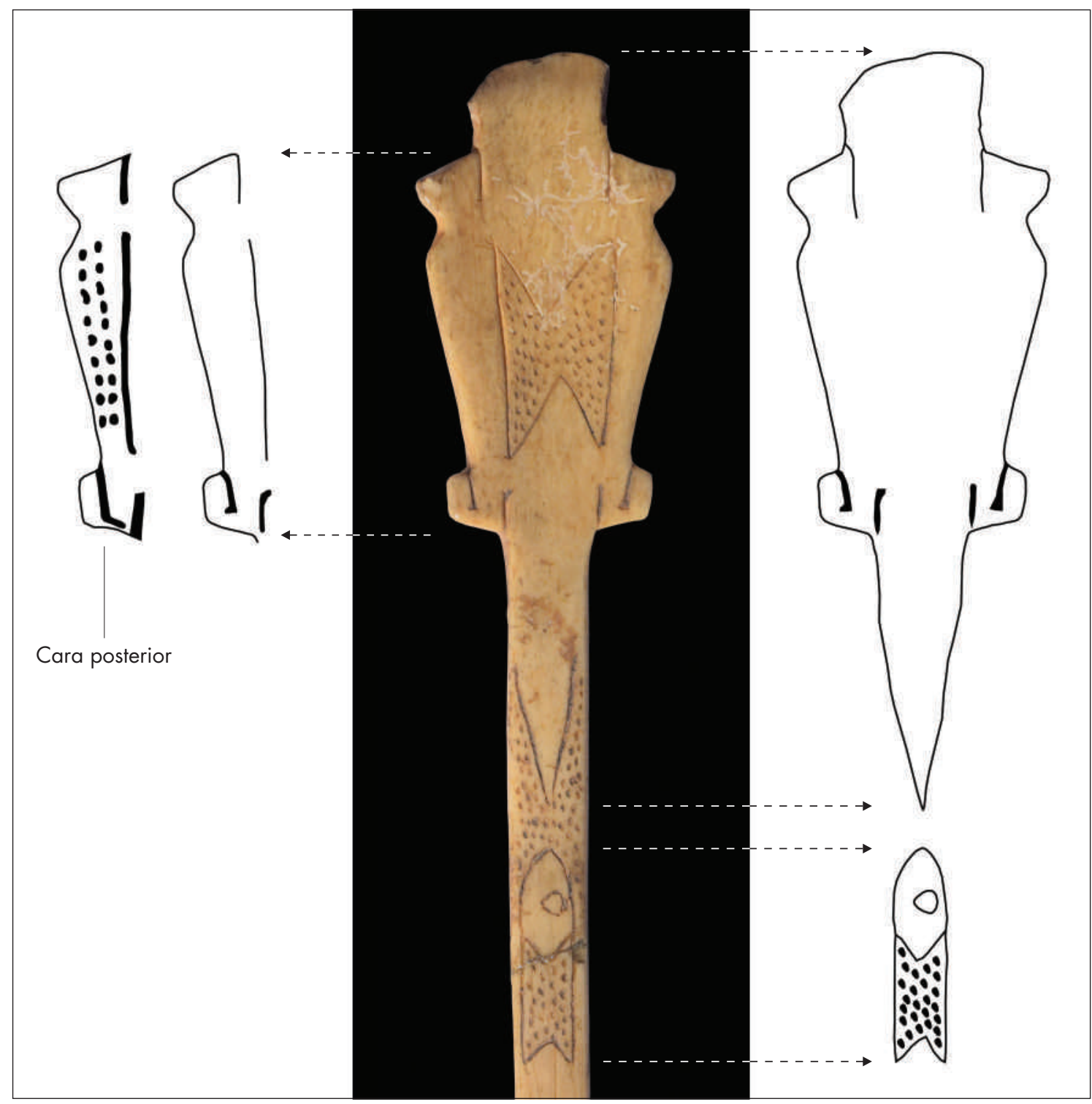

Figura 14. Diferentes lecturas en la decoración de la pieza $n^{\circ}$ 7. Figure 14. Different approaches in the decoration of piece $n^{\circ} 7$.

subtipo serían objetos importados en sus lugares de depositación final. Alternativamente, a través de vínculos sociales directos o indirectos sostenidos entre sus antiguos pobladores, las piezas cordobesas habrían sido importadas desde Chile o las chilenas introducidas desde Córdoba. ${ }^{1}$

De acuerdo a la segunda hipótesis, las espátulas de Córdoba serían copias o réplicas inspiradas en piezas chilenas, cuya materialización se relaciona con redes de interacción de media y larga distancia que conectaban a los habitantes de ambas regiones.
La tercera y última hipótesis supone la inexistencia de relaciones entre los antiguos habitantes de Córdoba y del Norte Chico. Las similitudes serían entonces el producto de una convergencia entre dos subtradiciones inconexas aunque integrantes de una misma macrotradición, que comparten determinadas prácticas culturales y significados. Esto habría involucrado, entre otros aspectos, el uso extendido de "espátulas con forma de topo" de diversos subestilos y decoraciones en numerosas áreas de los Andes centro-sur, meridionales y sus márgenes. 
Así, la convergencia sería el resultado de una opción común por la representación relativamente naturalista de los zoomorfos laterales.

\section{PRÁCTICAS INHALATORIAS Y REDES DE INTERACCIÓN EN EL CENTRO DE ARGENTINA}

Las tres hipótesis tienen implicancias cuya proyección será brevemente analizada. Para la primera, que define a las espátulas con forma de topo y zoomorfos laterales como objetos importados, un sustento clave provendría de las similitudes formales entre las piezas del Norte Chico chileno y las del centro de Argentina. Sin embargo, en este mismo terreno se notan diferencias que permiten distinguir al conjunto cordobés del trasandino. El receptáculo ancho y subtrapezoidal de algunas espátulas cordobesas difiere de la forma ovalada de las piezas chilenas (figs. 3 y 15; tabla 1). Asimismo, entre los zoomorfos laterales predominan las siluetas alargadas, afines a lagartos, sin indicación de manchas felínicas, lo cual señala un contraste con la mayoría de las piezas chilenas (figs. 3 y 8). Por ello, resulta más consistente considerar a los conjuntos del centro de Argentina y del Norte Chico como objetos de producción local y descartar esta primera hipótesis. La inexistencia de otros elementos contextuales que avalen una vinculación directa entre ambas regiones, como cerámica diaguita chilena u objetos procedentes de la costa del Pacífico en Córdoba, justifican en principio esta posición.

Por el contrario, existen expectativas consistentes con la segunda hipótesis, que concibe las espátulas de Córdoba como copias o réplicas de piezas de un subestilo particular, cuyo foco de desarrollo se habría situado en el Norte Chico de Chile. En este caso, las similitudes, y no la absoluta identidad formal, constituyen indicadores solidarios con el sentido de la hipótesis. Adicionalmente, tanto elementos contextuales como relativos al diseño de las piezas confluyen para señalar probables vínculos indirectos, con la coparticipación de grupos de ambos orígenes en redes sociales. Algunos detalles, como el punteado para señalar las manchas felínicas en la pieza 7 (fig. 13a) o la resolución de los ojos mediante un círculo con punto central en la pieza 11 (fig. 12b), revelarían procedimientos de copia antes que la importación de objetos exóticos (hipótesis 1) o invenciones independientes (hipótesis 3). Otros artefactos componentes de la parafernalia inhalatoria en Córdoba, tales como morteritos y tabletas de piedra, muestran rasgos estilísticos que no refieren al Norte Chico de Chile en lo específico, pero sí a espacios intermedios del norte de Cuyo y sur del NOA. Por su parte, el diseño y decoración de algunas espátulas cordobesas (piezas 3 y 7), con recursos como técnicas de negativo y de múltiples lecturas (figs. 9 y 14), también apuntan a vínculos occidentales y noroccidentales (González 1974, Gordillo 2009). Por medio de tales relaciones se habría tenido acceso al cebil manipulado con la parafernalia en cuestión. ${ }^{2}$ El conjunto de elementos sugiere la participación de los antiguos pobladores del centro de Argentina en redes sociales orientadas hacia el Norte Chico chileno (entre otros), con nodos en áreas intermedias (Pastor \& Boixadós 2016, Pastor $\&$ Tissera 2016). Estas áreas pudieron ser los espacios donde se materializaron los encuentros que produjeron el desarrollo de una subtradición local de "espátulas con forma de topo" y zoomorfos laterales en Córdoba.

En cuanto a la tercera hipótesis, la coparticipación de los diversos grupos en redes de interacción de media y larga distancia, así como la existencia de un marco regional de prácticas rituales y creencias compartidas, con uso común de espátulas óseas del subtipo "con forma de topo", pudo favorecer que surgieran subtradiciones de representación naturalista de las aletas laterales en más de una ocasión y de manera inconexa. ${ }^{3}$ En tal caso, las diferencias formales entre el conjunto cordobés y el del Norte Chico chileno serían indicadores consistentes con la hipótesis. Sin embargo, dos factores parecen debilitarla: algunos detalles que insinúan acciones de copiado (figs. 3a y f, 8d, 13a) y ciertos elementos contextuales que revelan posibles vínculos a través de áreas intermedias. Una línea promisoria para una mayor contextualización del problema será el análisis estilístico de otros elementos de la parafernalia inhalatoria en el centro de Argentina, como las tabletas de piedra, y su relación con objetos afines procedentes del norte de Cuyo y sur del NOA.

La intención en esta etapa no es afirmar una de las alternativas y descartar las restantes. Se puede orientar la investigación hacia alguna de las hipótesis, sin desechar elementos de otra o, asimismo, se pueden desarrollar otras posibilidades. Se ha señalado la dificultad de afirmarse en la idea de que, en el caso de Córdoba, se trate de piezas importadas desde Chile. Las diferencias formales entre los conjuntos del centro de Argentina y los del área andina parecen obstáculos insalvables, aun 


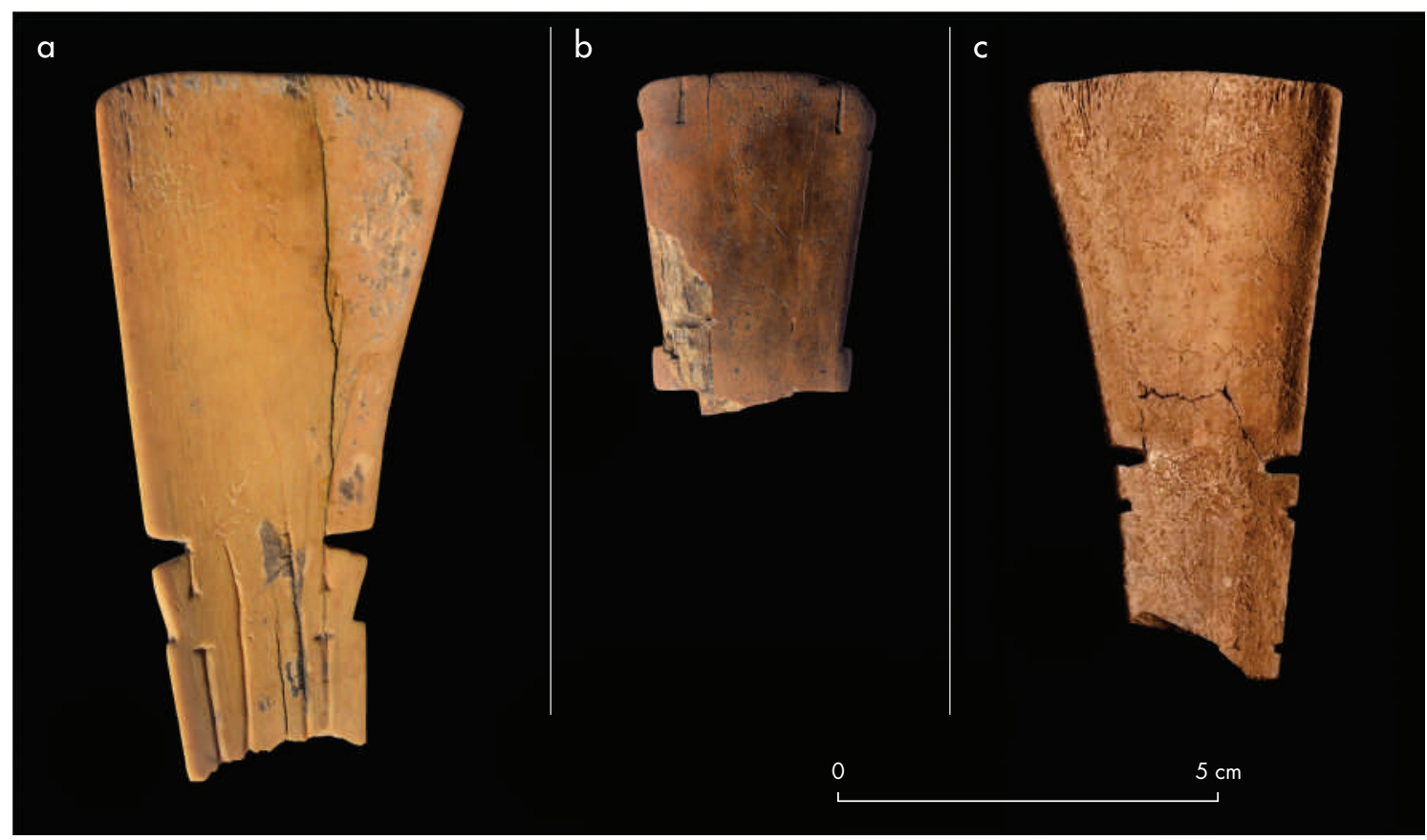

Figura 15: a) pieza $n^{\circ}$ 9; b) pieza $n^{\circ} 10$; c) pieza $n^{\circ}$ 6, procedentes de las costas del lago San Roque. Figure 15: $a$ ) piece $n^{\circ}$ 9; $b$ ) piece $n^{\circ}$ 10 ; c) piece $n^{\circ} 6$, from the San Roque lake shore.

cuando otros elementos contextuales, hoy inexistentes, puedan sumarse en el futuro.

De un modo general, las prácticas inhalatorias en el centro de Argentina habrían presentado referencias y coparticipación en un marco de tradiciones culturales extendidas en regiones situadas hacia el occidente y noroccidente. Esto se advierte por el acceso y consumo de un recurso no local como el cebil y por el diseño de los artefactos que integraban la parafernalia destinada a su manipulación y consumo, la que habría incluido a las espátulas óseas del subtipo "con forma de topo", en particular de la variedad "con aditamentos zoomorfos laterales".

Esta investigación se concibe como un punto de partida, tras la reunión de un primer corpus de materiales y la confrontación entre las expectativas de tres hipótesis diferenciadas. Tales propuestas podrán ser desarrolladas (o desechadas) cuando se sumen nuevos datos, especialmente piezas con mayores controles contextuales (p.e., estratigráficos). Más allá de estos objetos, otras líneas arqueológicas contribuirán al conocimiento de las redes de interacción extrarregionales a través de las cuales circularon personas, materias primas, bienes manufacturados e información. Entre ellas, es necesario sistematizar el análisis de otros artefactos componentes de la parafernalia inhalatoria, como morteritos, tabletas de piedra y tubos de hueso. Asimismo, los estudios de arte rupestre en curso aportarán datos relevantes para conocer tanto los vínculos o conexiones entre las diferentes áreas como la proyección regional de determinados marcos ideológicos.

\section{NOTAS}

${ }^{1}$ Una posibilidad pudo desarrollarse durante la expansión y dominio inka (siglo xv y comienzos del xvI), momento en que poblaciones de origen diaguita chileno habrían jugado un papel relevante en el control estatal de regiones trasandinas y en la negociación de sus fronteras (García 2010).

${ }^{2}$ La zona más cercana con presencia de cebil se ubica en las sierras de Ancasti (Catamarca), ca. 280-350 km al noroeste del área de distribución de las espátulas cordobesas (fig. 5). Fuentes escritas del siglo xvi señalan el consumo inhalatorio de cebil entre los grupos originarios del centro de Argentina y sugieren el acceso al mismo a través de redes de intercambio, ya que la especie no crece naturalmente en la zona (Berberián 1987, Montes 2008). 
${ }^{3}$ Los significados comprenderían a especies animales como los felinos y lagartos a través de nociones como la transmutación o metamorfosis, mediadas por fuerzas "felínicas".

ReConocimientos La investigación fue financiada por el CONICET (PIP 11220120100381Co). A los museos donde se conservan las piezas analizadas y a sus directores por cederlos para su estudio: Silvia Ledda (Museo Arqueológico Numba Charava, Villa Carlos Paz), Arturo Ferraretto (Museo Camín Cosquín), Rodolfo Herrero (Museo Aníbal Montes, Río Segundo) y Nelso Lenarduzzi (Museo Jesuítico Nacional, Jesús María). A Luis Tissera por las gestiones realizadas. Inés Gordillo, Helena Horta, Norma Ratto, Marina Sprovieri y Myriam Tarragó respondieron amablemente a nuestras inquietudes y aportaron información. A los evaluadores externos, por su trabajo que permitió mejorar la versión final.

\section{REFERENCIAS}

Аmbrosetti, J. 1907. Exploraciones arqueológicas en la ciudad prehistórica de La Paya (valle Calchaquí, Pcia. de Salta). Revista de la Universidad de Buenos Aires vin: 5-534. Buenos Aires.

Bennett, W. 1946. The atacameño. En Handbook of South American Indians, J. Steward, Ed., volumen 2, pp. 599-618. Washington: Smithsonian Institution, Bureau of American Ethnology, Bulletin 143.

Berberián, E. 1987. Crónicas del Tucumán. Siglo Xvi. Córdoba: Comechingonia.

Berenguer, J. 1987. Consumo nasal de alucinógenos en Tiwanaku: una aproximación iconográfica. Boletín del Museo Chileno de Arte Precolombino 2: 33-53. Santiago.

Boman, E. 1908. Antiquités de la région andine de la République Argentine et du Désert D’atacama. Paris: Imprimerie Nationale.

Casanova, E. 1939. La Quebrada de Humahuaca. En Historia de la nación Argentina, Academia Nacional de la Historia, Ed., vol. I, pp. 225-254. Buenos Aires: El Ateneo.

Castillo, G. 1992. Evidencias sobre uso de narcóticos en el norte semiárido chileno: catastro regional. Boletín del Museo Regional de Atacama 4: 105-160. Copiapó

GARcía, A. 2010. Modelo hipotético del proceso de anexión de Cuyo al Tawantinsuyu y la participación de los diaguitas chilenos. En Arqueología argentina en el Bicentenario de la Revolución de Mayo. xvir Congreso Nacional de Arqueología Argentina, J. Bárcena \& H. Chiavazza, Eds., tomo v, pp. 1771-1776. Mendoza: Universidad Nacional de Cuyo.

González, A. 1974. Arte, estructura y arqueología. Análisis de figuras duales y anatrópicas del Noroeste Argentino. Buenos Aires: Nueva Visión.

Gordillo, I. 2009. Dominios y recursos de la imagen. Iconografía cerámica del valle de Ambato. Estudios Atacameños 37: 99-121. San Pedro de Atacama.
Horta, H. 2012. El estilo circumpuneño en el arte de la parafernalia alucinógena prehispánica (Atacama y Noroeste Argentino). Estudios Atacameños 43: 5-34. San Pedro de Atacama.

Horta, H. 2014. Lo propio y lo ajeno. Definición del estilo San Pedro en la parafernalia alucinógena de los oasis del Salar de Atacama. Chungara 46 (4): 559-583. Arica.

IBARRA, D. 1971. Argentina indígena \& prehistoria americana. Buenos Aires: Tipográfica Editora Argentina.

LAFón, C. 1956-1957. Sobre algunos artefactos de hueso de la Quebrada de Humahuaca. Runa viII (2): 203-231. Buenos Aires.

Latchman, R. 1938. Arqueología de la región atacameña. Santiago: Prensas de la Universidad de Chile.

Llagostera, A. 2006. Contextualización e iconografía de las tabletas psicotrópicas tiwanaku de San Pedro de Atacama. Chungara 38 (1): 83-111. Arica.

Llagostera, A. 2015. Albores del psicotropismo en San Pedro de Atacama. Pipas vs. tabletas. Chungara 47 (3): 489-505. Arica.

Marcellino, A., E. Berberián \& J. Pérez. 1967. El yacimiento arqueológico de Los Molinos (Dpto. Calamuchita, Córdoba). Córdoba: Instituto de Antropología xxvi-Universidad Nacional de Córdoba.

Marengo, C. 1954. El antigal de Los Amarillos (Quebrada de Yacoraite, Provincia de Jujuy). Buenos Aires: Instituto de Arqueología II.

Michieli, C. 2013. Parafernalia para la consumición de psicoactivos hallada en tumbas prehispánicas de San Juan (Argentina). En Arqueología y etnohistoria del centro-oeste argentino. Publicación de las IX Jornadas de Investigadores en Arqueología y Etnohistoria del centro-oeste del País, A. Rocchietti, M. Yedro \& E. Olmedo, Eds., pp. 147-157. Río Cuarto: Universidad Nacional de Río Cuarto.

Montes, A. 2008. Indígenas y conquistadores de Córdoba. Buenos Aires: Isquitipe.

Motsny, G. 1952. Una tumba de Chiuchiu. Boletín del Museo Nacional de Historia Natural xxvi (1): 1-55. Saniago.

PAstor, S. \& R. Boixadós. 2016. Arqueología y etnohistoria: diálogos renovados en torno a las relaciones entre las sociedades de los llanos riojanos y las sierras noroccidentales de Córdoba (Período Prehispánico Tardío y Colonial Temprano). Diálogo Andino 49: 311-328. Arica.

Pastor, S. \& L. Tissera. 2016. Iconografía andina en los procesos de integración y legitimación política de comunidades prehispánicas de las Sierras de Córdoba. Arqueología 22 (1): 169-191. Buenos Aires.

Pazos, B. \& M. Giannoni. 1969. Una "cuchara" de hueso. Descripción e inferencias. Antiquitas Ix: 10-11. Córdoba.

Sempé, M. 1983. Mishma n 7. Sitio incaico del valle de Abaucán, Dto. Tinogasta, Pcia. Catamarca. Revista del Museo de La Plata VIII (65): 405-438. La Plata.

Serrano, A. 1945. Los comechingones. Córdoba: Instituto de Arqueología, Lingüística y Folklore Dr. Pablo Cabrera, Universidad Nacional de Córdoba. 
Sprovieri, M. 2008-2009. Alucinaciones en circulación. Una mirada a la interacción surandina tardía desde las tabletas y tubos de La Paya (valle Calchaquí, Salta). Anales de Arqueología y Etnología 63-64: 81-105. Mendoza.

Tarragó, M., L. González \& P. Peláez. 1997. El consumo de alucinógenos en el noroeste prehispánico. Evidencias en contextos funerarios. En Actas de las Jornadas de Antropología de la Cuenca del Plata, tomo III, pp. 140-148. Rosario: Universidad Nacional de Rosario.

Torres, C. 1986. Tabletas para alucinógenos en Sudamérica: tipología, distribución y rutas de difusión. Boletín del Museo Chileno de Arte Precolombino 1: 37-35. Santiago. 